\title{
Chiral multifunctional thiourea-phosphine catalyzed asymmetric [3 + 2] annulation of Morita-Baylis-Hillman carbonates with maleimides
}

\author{
Hong-Ping Deng ${ }^{1}$, De Wang ${ }^{2}$, Yin Wei ${ }^{1}$ and Min Shi ${ }^{* 1,2, \S}$
}

\section{Letter}

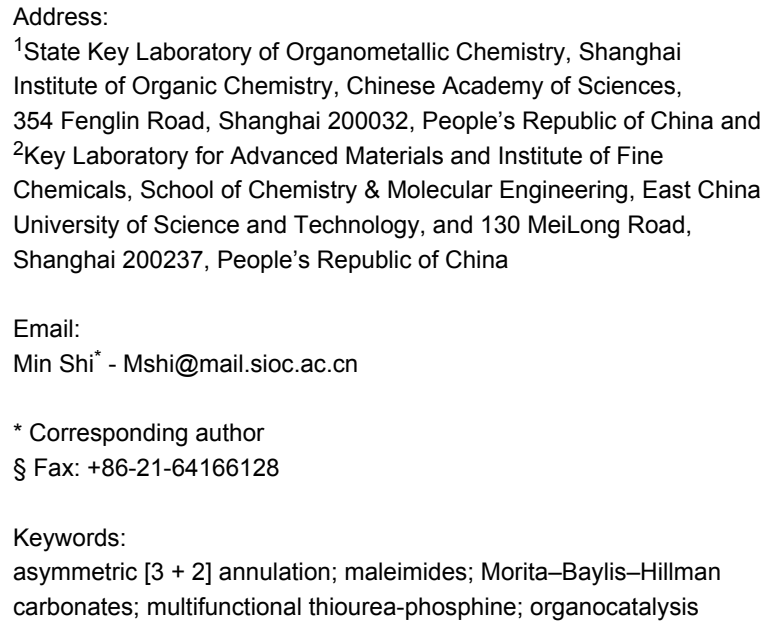

${ }^{1}$ State Key Laboratory of Organometallic Chemistry, Shanghai Institute of Organic Chemistry, Chinese Academy of Sciences, 354 Fenglin Road, Shanghai 200032, People's Republic of China and ${ }^{2}$ Key Laboratory for Advanced Materials and Institute of Fine Chemicals, School of Chemistry \& Molecular Engineering, East China University of Science and Technology, and 130 MeiLong Road, Shanghai 200237, People's Republic of China

\begin{abstract}
We have developed a multifunctional thiourea-phosphine catalyzed asymmetric [3 + 2] annulation of Morita-Baylis-Hillman $(\mathrm{MBH})$ carbonates with maleimides, which can efficiently construct functionalized cyclopentenes bearing three contiguous stereocenters in moderate to excellent yields and excellent diastereo- and enantioselectivities. A plausible mechanism has been also proposed on the basis of control experiments and previous literature.
\end{abstract}

\section{Introduction}

Highly functionalized cyclopentene derivatives are important subunits in a variety of biologically active molecules and have attracted the broad attention of synthetic and pharmaceutical chemists $[1,2]$. Among numerous synthetic approaches, phosphine-mediated [3+2] annulation of electron-deficient olefins is an efficient method to construct this interesting structural motif [3-10]. According to the pioneering work of $\mathrm{Lu}$ [11-20], all phosphine-mediated [3+2] annulations proceeded through an important intermediate "1,3-dipolar synthon". The forma- tion of a 1,3-dipolar synthon by using a catalytic amount of phosphines have been directed toward the following two paths: phosphines attack the middle carbon atom of allenes to produce the 1,3-dipolar synthon (Scheme 1, reaction 1), and phosphines add to the $\beta$-position of MBH carbonate to remove carbon dioxide and tert-butanol, affording the 1,3-dipolar synthon (Scheme 1, reaction 2). Concerning the asymmetric [3+2] annulation catalyzed by chiral phosphines, Zhang and co-workers first reported the asymmetric $[3+2]$ annulation of 
allenoates with acrylates catalyzed by a bicyclic chiral phosphine in 1997 [21]. Moreover, Fu [22-24], Marinetti [25-28], Lu [29-31] and other researchers [32-36] have also developed asymmetric $[3+2]$ annulations of allenoates to give the corresponding cyclopentene derivatives in good yields with excellent enantioselectivities [37].

$\mathrm{R}^{1}$

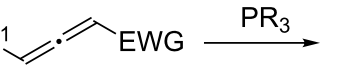<smiles>[R]C(=O)C=CC(C)C</smiles>

reaction 1

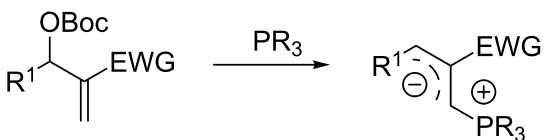

Scheme 1: Paths to the formation of 1,3-dipolar synthons by using a catalytic amount of phosphines.

On the other hand, some examples of phosphine-catalyzed $[3+2]$ annulation of MBH carbonates with electron-deficient alkenes have been reported in the literature recently. $\mathrm{Lu}$ and co-workers first disclosed the formation of 1,3-dipoles through phosphine-catalyzed MBH carbonates under mild conditions, which can efficiently react with various electron-deficient olefins to afford the desired cyclic products in good yields along with high regioselectivities, through intra- and intermolecular $[3+n]$ annulations [38-47]. To the best of our knowledge, there is little in the literature regarding the asymmetric version of this reaction. In 2010, Tang and co-workers reported the first example of asymmetric intramolecular [3 3 ] annulations of MBH carbonates tethered with another electron-deficient olefin in the presence of spirobiindane-based chiral phosphines, giving the corresponding cycloadducts in good yields along with high ee values [48]. Barbas and co-workers first reported asymmetric intermolecular [3 3 ] cycloaddition of MBH carbonates with methyleneindolinones to afford the corresponding spirocyclopentaneoxindoles in good yields and high ee values in 2011 [49]. Moreover, $\mathrm{Lu}$ and co-workers have recently explored a series of thiourea-phosphine catalysts derived from L-threonine, which are effective catalysts in the [3+2] annulation of $\mathrm{MBH}$ carbonates with isatylidene malononitriles to give the desired products in high yields with high enantioselectivities [50]. Furthermore, our group recently also synthesized a series of L-phenylalanine-derived multifunctional thiourea-phosphine catalysts and used them in the $[3+2]$ annulation of $\mathrm{MBH}$ carbonates with trifluoroethylidenemalonates to give the cycloadducts in high yields along with excellent diastereo- and enantioselectivities [51]. Herein we wish to report the development of a multifunctional thiourea-phosphine catalyzed asymmetric [3+2] annulation of MBH carbonates with maleimides, which can efficiently construct functionalized cyclopentene derivatives bearing three contiguous stereocenters in moderate to excellent yields along with excellent diastereo- and enantioselectivities.

\section{Results and Discussion}

In our previous work, it was shown that chiral multifunctional thiourea-phosphines were excellent catalysts for the asymmetric aza-MBH reaction, asymmetric allylic substitution of $\mathrm{MBH}$ adducts, and asymmetric [3+2] annulation of $\mathrm{MBH}$ carbonates with electron-deficient olefins [52-56]. Hence, we initially used multifunctional thiourea-phosphine (TP), which could be easily prepared from L-phenylalanine in four steps [57], as a catalyst to investigate the asymmetric [3+2] annulation of $N$-phenylmaleimide (1a) with $\mathrm{MBH}$ carbonate $\mathbf{2 a}$ in toluene at room temperature. We were pleased to find that the corresponding highly functionalized cyclopentene 3a was obtained in $54 \%$ yield with $96 \%$ ee after $24 \mathrm{~h}$ (Table 1, entry 1). The examination of solvent effects revealed that toluene is the best solvent (Table 1, entries 2-4). Increasing the ratio of $\mathbf{1 a} / \mathbf{2 a}$ from $1: 1.3$ to $2: 1$ afforded $3 \mathbf{a}$ in $74 \%$ yield and $96 \%$ ee, while continuously increasing the ratio of $\mathbf{1 a} / \mathbf{2} \mathbf{a}$ to $4: 1$ gave $\mathbf{3 a}$ in lower yield (Table 1, entries 5 and 6).

Having identified the optimal reaction conditions, we next set out to examine the scope and limitations of this asymmetric $[3+2]$ annulation of maleimides with MBH carbonates, and the results are summarized in Table 2 . All of the reactions proceeded smoothly under the optimal conditions, providing annulation products with good to excellent diastereo- and enantioselectivities. Using MBH carbonate $\mathbf{2 a}$ as a substrate, we examined its reaction with maleimides $\mathbf{1 b}-\mathbf{1 e}$ and found that the reactions proceeded smoothly to give the corresponding products $\mathbf{3 b}-\mathbf{3 e}$ in excellent yields along with excellent ee values (Table 2, entries 2-5). Taking $N$-benzhydrylmaleimide (1d) as a substrate, we found that substrates with an electron-withdrawing substituent on the aromatic ring of $\mathrm{MBH}$ carbonates 2 produced $\mathbf{3 f}$ and $\mathbf{3 g}$ in good yields and excellent ee values (Table 2, entries 6 and 7), and MBH carbonate $2 \mathbf{d}$ gave the corresponding annulation product $3 \mathbf{h}$ in $3: 1 \mathrm{dr}$ value with $74 \%$ yield of major isomer and $97 \%$ ee (Table 2, entry 8 ). A variety of MBH carbonates 2 having either electron-donating or -withdrawing groups as substituents at the para- and meta-position of the benzene ring and $N$-methylmaleimide (1b) underwent this asymmetric [3 +2$]$ annulation smoothly, affording the corresponding products 3 in moderate to excellent yields with excellent ee values upon lengthening of the reaction time (Table 2, entries 9-11, 13-15). Substrate $\mathbf{2 k}$, incorporating a heteroaromatic group, could also react with $\mathbf{1 b}$ under the same reaction conditions, giving the corresponding cyclopentene $3 \mathbf{p}$ in $69 \%$ yield with $96 \%$ ee, and substrates $\mathbf{2 l}$ and $\mathbf{2 m}$ derived from 
Table 1: Optimization of the reaction conditions for asymmetric [3+2] annulation of $\mathrm{MBH}$ carbonates and maleimides.<smiles>C=C(OCC)C(OC(=O)OCC)c1ccc([N+](=O)[O-])cc1</smiles>

\begin{tabular}{lllll}
\hline entry $^{\mathrm{a}}$ & $\mathbf{1 a / 2 a}$ & solvent & yield $(\%)^{\mathrm{b}}$ & ee $(\%)^{\mathrm{c}}$ \\
\hline 1 & $1 / 1.3$ & toluene & 54 & 96 \\
2 & $1 / 1.3$ & $\mathrm{CHCl}_{3}$ & 54 & 96 \\
3 & $1 / 1.3$ & $\mathrm{THF}$ & 25 & 90 \\
4 & $1 / 1.3$ & $\mathrm{CH}_{3} \mathrm{CN}$ & 12 & 43 \\
$5^{\mathrm{d}}$ & $2 / 1$ & toluene & 74 & 96 \\
$6^{\mathrm{e}}$ & $4 / 1$ & toluene & 62 & 96 \\
\hline
\end{tabular}

${ }^{a}$ Reactions were performed with $1 \mathrm{a}(0.1 \mathrm{mmol})$ and $\mathbf{2 a}(0.13 \mathrm{mmol})$ in toluene $(1.0 \mathrm{~mL})$ at room temperature for $24 \mathrm{~h}$. ${ }^{\mathrm{b}} / \mathrm{solated}$ yield of major isomer. 'Determined by chiral HPLC. dReaction was performed with $1 \mathrm{a}(0.2 \mathrm{mmol})$ and $2 \mathrm{a}(0.1 \mathrm{mmol})$ in toluene $(1.0 \mathrm{~mL})$ at room temperature for $24 \mathrm{~h}$. eReaction was performed with $1 \mathrm{a}(0.4 \mathrm{mmol})$ and $2 \mathrm{a}(0.1 \mathrm{mmol})$ in toluene $(1.0 \mathrm{~mL})$ at room temperature for $24 \mathrm{~h}$.

Table 2: Substrate scope of asymmetric [3+2] annulation.

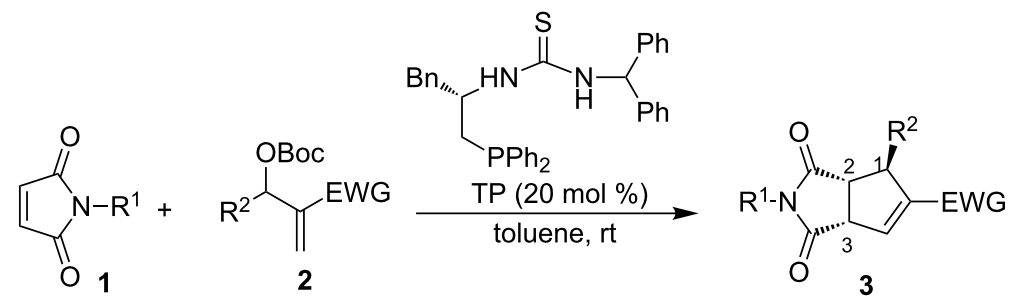

\begin{tabular}{|c|c|c|c|c|c|}
\hline entry ${ }^{a}$ & $\mathrm{R}^{1}$ & $\mathrm{R}^{2}$ & EWG & yield $(\%)^{b}$ & ee $(\%)^{c}$ \\
\hline 1 & $1 \mathrm{a}, \mathrm{Ph}$ & $2 \mathrm{a}, 4-\mathrm{NO}_{2} \mathrm{C}_{6} \mathrm{H}_{4}$ & $\mathrm{CO}_{2} \mathrm{Et}$ & $3 a, 74$ & 96 \\
\hline 2 & $1 \mathrm{~b}, \mathrm{Me}$ & $2 a, 4-\mathrm{NO}_{2} \mathrm{C}_{6} \mathrm{H}_{4}$ & $\mathrm{CO}_{2} \mathrm{Et}$ & $3 b, 99$ & 98 \\
\hline 3 & $1 \mathrm{c}, \mathrm{Bn}$ & $2 a, 4-\mathrm{NO}_{2} \mathrm{C}_{6} \mathrm{H}_{4}$ & $\mathrm{CO}_{2} \mathrm{Et}$ & $3 c, 86$ & 94 \\
\hline 4 & 1d, benzhydryl & $2 \mathrm{a}, 4-\mathrm{NO}_{2} \mathrm{C}_{6} \mathrm{H}_{4}$ & $\mathrm{CO}_{2} \mathrm{Et}$ & $3 d,>99$ & 98 \\
\hline 5 & 1e, 1-methylnaphthyl & $2 \mathrm{a}, 4-\mathrm{NO}_{2} \mathrm{C}_{6} \mathrm{H}_{4}$ & $\mathrm{CO}_{2} \mathrm{Et}$ & $\mathbf{3 e}, 91$ & 96 \\
\hline 6 & 1d, benzhydryl & 2b, 3- $\mathrm{NO}_{2} \mathrm{C}_{6} \mathrm{H}_{4}$ & $\mathrm{CO}_{2} \mathrm{Et}$ & $3 f, 87$ & 94 \\
\hline 7 & 1d, benzhydryl & 2c, $4-\mathrm{CNC}_{6} \mathrm{H}_{4}$ & $\mathrm{CO}_{2} \mathrm{Et}$ & $3 g, 84$ & 96 \\
\hline $8^{\mathrm{d}, \mathrm{e}}$ & 1d, benzhydryl & 2d, $4-\mathrm{BrC}_{6} \mathrm{H}_{4}$ & $\mathrm{CO}_{2} \mathrm{Et}$ & $3 h, 74$ & 97 \\
\hline $9^{e}$ & 1b, Me & 2d, $4-\mathrm{BrC}_{6} \mathrm{H}_{4}$ & $\mathrm{CO}_{2} \mathrm{Et}$ & $3 \mathbf{i}, 79$ & 95 \\
\hline $10^{e}$ & $1 \mathrm{~b}, \mathrm{Me}$ & $2 \mathbf{e}, 4-\mathrm{ClC}_{6} \mathrm{H}_{4}$ & $\mathrm{CO}_{2} \mathrm{Et}$ & $3 \mathbf{j}, 90$ & 96 \\
\hline $11^{e}$ & $1 \mathrm{~b}, \mathrm{Me}$ & $2 f, 3-\mathrm{ClC}_{6} \mathrm{H}_{4}$ & $\mathrm{CO}_{2} \mathrm{Et}$ & $3 k, 81$ & 97 \\
\hline $12^{f}$ & $1 \mathrm{~b}, \mathrm{Me}$ & $2 \mathrm{~g}, 2-\mathrm{ClC}_{6} \mathrm{H}_{4}$ & $\mathrm{CO}_{2} \mathrm{Et}$ & $3 \mathbf{3}, 39$ & 73 \\
\hline $13^{f}$ & $1 \mathrm{~b}, \mathrm{Me}$ & $2 \mathrm{~h}, \mathrm{C}_{6} \mathrm{H}_{5}$ & $\mathrm{CO}_{2} \mathrm{Et}$ & $3 m, 74$ & 94 \\
\hline $14^{f}$ & 1b, Me & $2 \mathbf{i}, 4-\mathrm{MeC}_{6} \mathrm{H}_{4}$ & $\mathrm{CO}_{2} \mathrm{Et}$ & $3 n, 64$ & 96 \\
\hline $15^{f}$ & $1 \mathrm{~b}, \mathrm{Me}$ & $2 \mathrm{j}, 4-\mathrm{MeOC}_{6} \mathrm{H}_{4}$ & $\mathrm{CO}_{2} \mathrm{Et}$ & 3o, 55 & 98 \\
\hline $16^{f}$ & 1b, Me & $2 k, 2$-furyl & $\mathrm{CO}_{2} \mathrm{Et}$ & $3 p, 69$ & 96 \\
\hline 17 & $1 \mathrm{~b}, \mathrm{Me}$ & 2I, 4- $\mathrm{NO}_{2} \mathrm{C}_{6} \mathrm{H}_{4}$ & COMe & $3 q,>99$ & 97 \\
\hline 18 & $1 \mathrm{~b}, \mathrm{Me}$ & $2 \mathrm{~m}, 4-\mathrm{NO}_{2} \mathrm{C}_{6} \mathrm{H}_{4}$ & COMe & $3 r, 92$ & 98 \\
\hline $19^{f}$ & $1 \mathrm{~b}, \mathrm{Me}$ & 2n, $\left(\mathrm{CH}_{3}\right)_{2} \mathrm{CH}$ & $\mathrm{CO}_{2} \mathrm{Et}$ & - & - \\
\hline
\end{tabular}

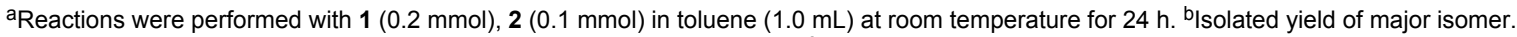
${ }^{c}$ Determined by chiral HPLC. ${ }^{d} d r=3: 1$. e Reaction was performed for $36 \mathrm{~h}$. ${ }^{f}$ Reaction was performed for $48 \mathrm{~h}$. 
methyl vinyl ketone (MVK) afforded the corresponding annulation products $\mathbf{3 q}$ and $\mathbf{3 r}$ in excellent yields and ee values under the standard conditions (Table 2, entries 16-18). The absolute configuration of the major product $\mathbf{3 r}$ was determined as $(1 S, 2 R, 3 S)$ by X-ray crystal structure. Its ORTEP plot is shown in Figure 1 and the corresponding CIF data are presented in the Supporting Information File 2 [58]. As for MBH carbonate 2g,

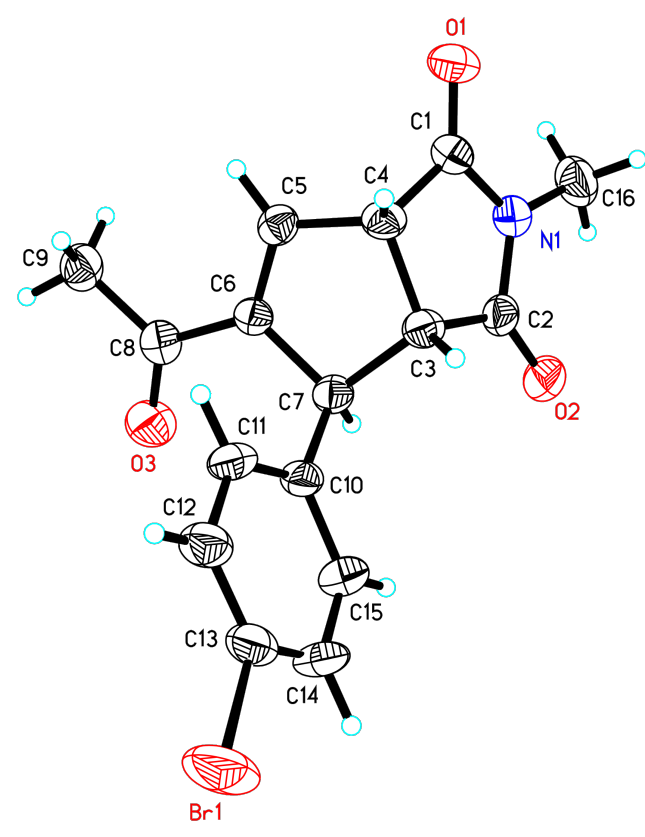

Figure 1: The ORTEP plot of compound 3r. having a chlorine substituent at the ortho-position of the aromatic ring, this produced $\mathbf{3 l}$ in lower yield and ee value, perhaps due to the steric effect; reaction of MBH carbonate $\mathbf{2 n}$ derived from isobutyraldehyde did not occur (entries 12 and 19). When we utilized dimethyl maleate or dimethyl fumarate instead of maleimides, it was found that the reactions could not be performed either.

As aforementioned, increasing the ratio of $\mathbf{1 a} / \mathbf{2} \mathbf{a}$ from $1: 1.3$ to $2: 1$ obtained the highest yield. In order to explain this finding, three control experiments were performed in $\mathrm{CDCl}_{3}$ and the results were studied by using ${ }^{31} \mathrm{P}$ NMR spectroscopy (Figure 2, also see Figure SI-1 in the Supporting Information File 1). The NMR studies revealed that catalyst TP seems to react with $N$-phenylmaleimide (1a) to form a new species (Figure 2, spectra b), which costs some maleimide 1a. Thus, the excess 1a has to be added in order to make the reaction complete. This is why increasing the ratio of $\mathbf{1} \mathbf{a} / \mathbf{2} \mathbf{a}$ raised the yield of product $\mathbf{3 a}$ (Table 1, entry 5). On the other hand, if too much maleimide 1a is used in this reaction, it will waste some of the catalyst TP, leading to a decrease in the yield of product 3a (Table 1, entry $6)$. The allylic phosphorus ylide species can be recognized in spectra $\mathrm{c}$ from the combination of $\mathbf{2 d}$ and TP (1:1) (Figure 2, also see Figure SI-1 in the Supporting Information File 1) [59].

As reported before [15,51], TP attacks MBH carbonate to afford allylic phosphorus ylide $\mathbf{I}$, which attacked the maleimide to produce intermediate II (Scheme 2). Since there is a steric effect between the phenyl group and the benzyl group in inter-

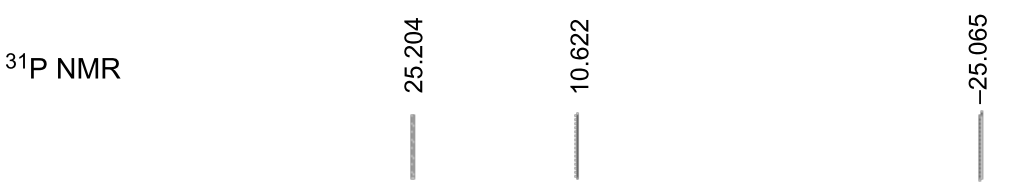

a) TP

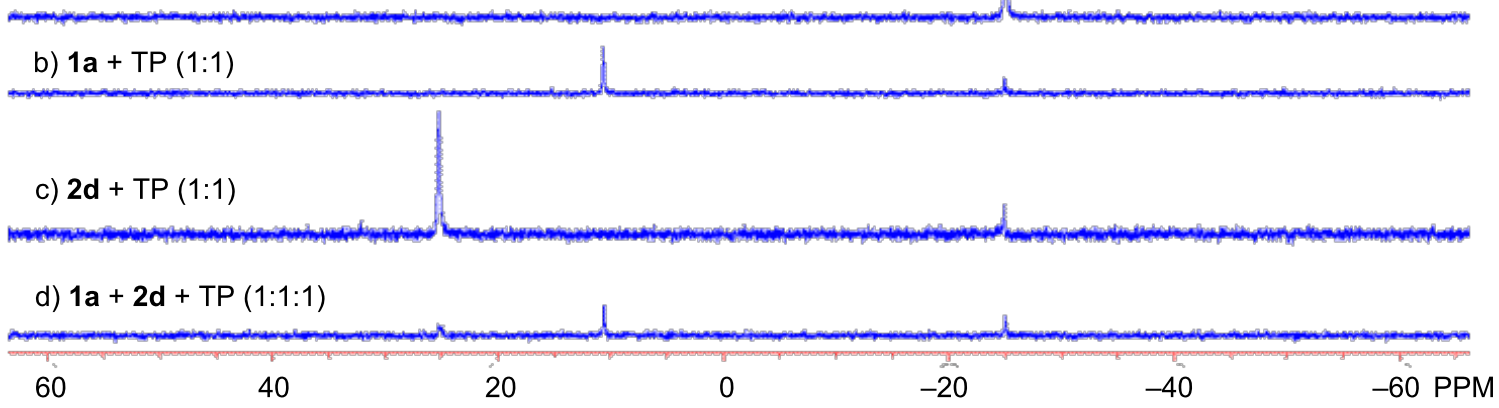




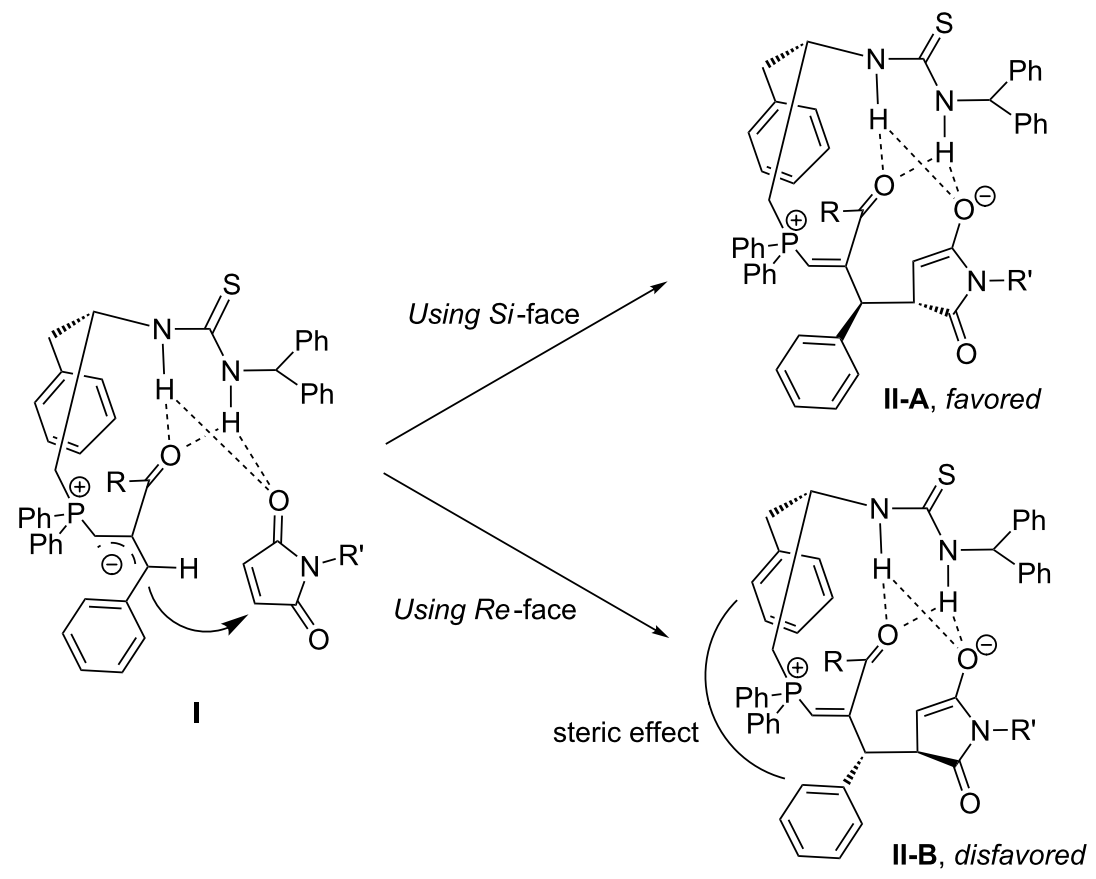

Scheme 2: Proposed transition models.

mediate II-B, allylic phosphorus ylide I using its $\mathrm{Si}$-face to attack maleimide is favored (intermediate II-A). Undergoing Michael addition and elimination of catalyst along with the double-bond formation, intermediate I affords the corresponding highly functionalized cyclopentene product and completes the catalytic cycle. The control experiments demonstrated that catalyst TP can react with maleimide, affording an unidentified complex and partially wasting maleimide and catalyst (spectra d in Figure 2). Hypothetically, the activity of the in situ generated allylic phosphorous ylide $\mathbf{I}$ is crucial for the yield of product. If the activity of phosphorous ylide is not high enough, it may deprotonate the NH proton in TP, which will cause the catalyst to lose activity (See Table 2, entries 12-16). In addition, if the phosphorous ylide is not active enough to react with maleimide, maleimide can directly react with the catalyst to form the other unidentified species as indicated in the ${ }^{31} \mathrm{P}$ NMR spectroscopy (spectra $\mathrm{b}$ in Figure 2), which may retard the desired catalytic cycle.

To illustrate the synthetic utility of these products 3 obtained from the above asymmetric $[3+2]$ annulation, the further transformation of $\mathbf{3 c}$ was performed in the presence of $\mathrm{RuCl}_{3}$ and $\mathrm{NaIO}_{4}$ under mild conditions (Scheme 3) [22,60]. Upon dihydroxylation of $\mathbf{3 c}$, the corresponding product $4 \mathbf{c}$ containing five stereocenters was produced in $69 \%$ yield and good diastereoselectivity on the basis of NMR spectroscopic data $(\mathrm{dr}=20: 1$, see Supporting Information File 1).

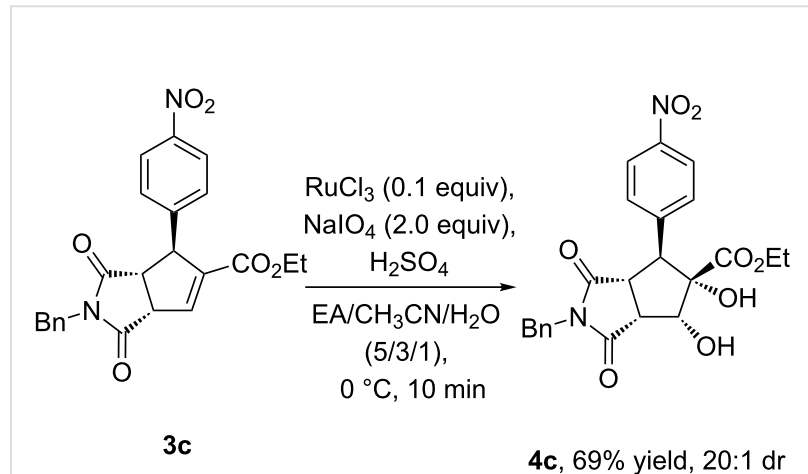

Scheme 3: Dihydroxylation of 3c.

\section{Conclusion}

In conclusion, we have developed a novel multifunctional thiourea-phosphine catalyzed asymmetric [3+2] annulation of MBH carbonates with maleimides, which can efficiently construct functionalized cyclopentenes bearing three contiguous stereocenters in moderate to excellent yields and excellent diastereo- and enantioselectivities, and the product can be efficiently transformed into a cyclopentane containing five stereocenters under mild conditions, which was difficult to construct by other synthetic methodologies. Current efforts are in progress to apply this new methodology to synthesize biologically active products. 


\section{Experimental}

\section{General procedure for asymmetric [3 +2$]$ annulation}

Under an argon atmosphere, a mixture of maleimide $\mathbf{1}$ $(0.2 \mathrm{mmol}), \mathrm{MBH}$ carbonate $2(0.2 \mathrm{mmol})$ and catalyst TP $(0.02 \mathrm{mmol}, 11 \mathrm{mg})$ in toluene $(1.0 \mathrm{~mL})$ was stirred at room temperature for 24-48 h. Then the solvent was removed under reduced pressure, and the residue was chromatographed on silica gel (elution with petroleum ether/EtOAc 10:1-4:1) to provide compound 3 .

\section{Supporting Information}

\section{Supporting Information File 1}

Experimental procedures and characterization data of compounds given in this article.

[http://www.beilstein-journals.org/bjoc/content/ supplementary/1860-5397-8-121-S1.pdf]

\section{Supporting Information File 2}

Crystal structure data of compound $\mathbf{3 r}$.

[http://www.beilstein-journals.org/bjoc/content/ supplementary/1860-5397-8-121-S2.pdf]

\section{Supporting Information File 3}

cif data of $\mathbf{3 r}$.

[http://www.beilstein-journals.org/bjoc/content/ supplementary/1860-5397-8-121-S3.cif]

\section{Acknowledgements}

We thank the Shanghai Municipal Committee of Science and Technology (11JC1402600), National Basic Research Program of China (973)-2010CB833302, and the National Natural Science Foundation of China for financial support (21072206, 20472096, 20872162, 20672127, 21121062 and 20732008) and Mr. Jie Sun for performing X-ray diffraction.

\section{References}

1. Hartley, R. C.; Caldwell, S. T. J. Chem. Soc., Perkin Trans. 12000, 477-501. doi:10.1039/A804421J

2. Wu, H.; Zhang, H.; Zhao, G. Tetrahedron 2007, 63, 6454-6461. doi:10.1016/j.tet.2007.03.031

3. Lu, X.; Zhang, C.; Xu, Z. Acc. Chem. Res. 2001, 34, 535-544. doi:10.1021/ar000253x

4. Methot, J. L.; Roush, W. R. Adv. Synth. Catal. 2004, 346, 1035-1050. doi:10.1002/adsc.200404087

5. Ye, L.-W.; Zhou, J.; Tang, Y. Chem. Soc. Rev. 2008, 37, 1140-1152. doi:10.1039/b717758e

6. Cowen, B. J.; Miller, S. J. Chem. Soc. Rev. 2009, 38, 3102-3116. doi:10.1039/b816700c

7. Marinetti, A.; Voituriez, A. Synlett 2010, 174-194. doi:10.1055/s-0029-1219157
8. Wei, Y.; Shi, M. Acc. Chem. Res. 2010, 43, 1005-1018. doi:10.1021/ar900271g

9. López, F.; Mascareñas, J. L. Chem.-Eur. J. 2011, 17, 418-428. doi:10.1002/chem.201002366

10. Zhao, Q.-Y.; Lian, Z.; Wei, Y.; Shi, M. Chem. Commun. 2012, 48, 1724-1732. doi:10.1039/c1cc15793k

11. Zhang, C.; Lu, X. J. Org. Chem. 1995, 60, 2906-2908. doi:10.1021/jo00114a048

12. Xu, Z.; Lu, X. J. Org. Chem. 1998, 63, 5031-5041. doi:10.1021/jo9723063

13. Xu, Z.; Lu, X. Tetrahedron Lett. 1999, 40, 549-552. doi:10.1016/S0040-4039(98)02405-8

14. Du, Y.; Lu, X. J. Org. Chem. 2003, 68, 6463-6465. doi:10.1021/jo034281f

15. Lu, Z.; Zheng, S.; Zhang, X.; Lu, X. Org. Lett. 2008, 10, 3267-3270. doi:10.1021/ol8011452

16. Zheng, S.; Lu, X. Org. Lett. 2008, 10, 4481-4484. doi:10.1021/ol801661y

17. Du, Y.; Lu, X.; Zhang, C. Angew. Chem., Int. Ed. 2003, 42, 1035-1037. doi:10.1002/anie.200390266

18. Zhu, X.-F.; Lan, J.; Kwon, O. J. Am. Chem. Soc. 2003, 125, 4716-4717. doi:10.1021/ja0344009

19. Tran, Y. S.; Kwon, O. J. Am. Chem. Soc. 2007, 129, 12632-12633. doi:10.1021/ja0752181

20. Na, R.; Jing, C.; Xu, Q.; Shi, J.; Jiang, H.; Wu, X.; Shi, J.; Zhong, J.; Wang, M.; Benitez, D.; Tkatchouk, E.; Goddard, W. A., III; Guo, H.; Kwon, O. J. Am. Chem. Soc. 2011, 133, 13337-13348. doi:10.1021/ja200231v

21. Zhu, G.; Chen, Z.; Jiang, Q.; Xiao, D.; Cao, P.; Zhang, X. J. Am. Chem. Soc. 1997, 119, 3836-3837. doi:10.1021/ja9644687

22. Wurz, R. P.; Fu, G. C. J. Am. Chem. Soc. 2005, 127, 12234-12235. doi:10.1021/ja053277d

23. Wilson, J. E.; Fu, G. C. Angew. Chem., Int. Ed. 2006, 45, 1426-1429 doi:10.1002/anie.200503312

24. Fujiwara, Y.; Fu, G. C. J. Am. Chem. Soc. 2011, 133, 12293-12297. doi:10.1021/ja2049012

25. Mercier, E.; Fonovic, B.; Henry, C.; Kwon, O.; Dudding, T. Tetrahedron Lett. 2007, 48, 3617-3620. doi:10.1016/j.tetlet.2007.03.030

26. Voituriez, A.; Panossian, A.; Fleury-Brégeot, N.; Retailleau, P.; Marinetti, A. J. Am. Chem. Soc. 2008, 130, 14030-14031. doi:10.1021/ja806060a

27. Voituriez, A.; Panossian, A.; Fleury-Brégeot, N.; Retailleau, P.; Marinetti, A. Adv. Synth. Catal. 2009, 351, 1968-1976. doi:10.1002/adsc.200900193

28. Voituriez, A.; Pinto, N.; Neel, M.; Retailleau, P.; Marinetti, A. Chem.-Eur. J. 2010, 16, 12541-12544. doi:10.1002/chem.201001791

29. Han, X.; Wang, Y.; Zhong, F.; Lu, Y. J. Am. Chem. Soc. 2011, 133, 1726-1729. doi:10.1021/ja1106282

30. Han, X.; Wang, S.-X.; Zhong, F.; Lu, Y. Synthesis 2011, 1859-1964. doi:10.1055/s-0030-1260460

31. Han, X.; Zhong, F.; Wang, Y.; Lu, Y. Angew. Chem., Int. Ed. 2012, 51, 767-770. doi:10.1002/anie.201106672

32. Cowen, B. J.; Miller, S. J. J. Am. Chem. Soc. 2007, 129, 10988-10989. doi:10.1021/ja0734243

33. Fang, Y.-Q.; Jacobsen, E. N. J. Am. Chem. Soc. 2008, 130, 5660-5661. doi:10.1021/ja801344w

34. Xiao, H.; Chai, Z.; Zheng, C.-W.; Yang, Y.-Q.; Liu, W.; Zhang, J.-K.; Zhao, G. Angew. Chem., Int. Ed. 2010, 49, 4467-4470. doi:10.1002/anie.201000446 
35. Sampath, M.; Loh, T.-P. Chem. Sci. 2010, 1, 739-742. doi:10.1039/c0sc00123f

36. Steurer, M.; Jensen, K. L.; Worgull, D.; Jørgensen, K. A. Chem.-Eur. J. 2012, 18, 76-79. doi:10.1002/chem.201103502

37. Xiao, H.; Chai, Z.; Wang, H.-F.; Wang, X.-W.; Cao, D.-D.; Liu, W.; Lu, Y.-P.; Yang, Y.-Q.; Zhao, G. Chem.-Eur. J. 2011, 17, 10562-10565. doi:10.1002/chem.201100850

38. Du, Y.; Feng, J.; Lu, X. Org. Lett. 2005, 7, 1987-1989. doi:10.1021/ol050443d

39. Feng, J.; Lu, X.; Kong, A.; Han, X. Tetrahedron 2007, 63, 6035-6041. doi:10.1016/j.tet.2007.02.115

40. Zheng, S.; Lu, X. Tetrahedron Lett. 2009, 50, 4532-4535. doi:10.1016/j.tetlet.2009.05.085

41. Zheng, S.; Lu, X. Org. Lett. 2009, 11, 3978-3981. doi:10.1021/ol901618h

42. Ye, L.-W.; Sun, X.-L.; Wang, Q.-G.; Tang, Y. Angew. Chem., Int. Ed. 2007, 46, 5951-5954. doi:10.1002/anie.200701460

43. Han, X.; Ye, L.-W.; Sun, X.-L.; Tang, Y. J. Org. Chem. 2009, 74, 3394-3397. doi:10.1021/jo9001917

44. Zhou, R.; Wang, J.; Song, H.; He, Z. Org. Lett. 2011, 13, 580-583. doi:10.1021/ol102738b

45. Chen, Z.; Zhang, J. Chem.-Asian J. 2010, 5, 1542-1545. doi:10.1002/asia.201000193

46. Xie, P.; Huang, Y.; Chen, R. Org. Lett. 2010, 12, 3768-3771. doi:10.1021/ol101611v

47. Tian, J.; Zhou, R.; Sun, H.; Song, H.; He, Z. J. Org. Chem. 2011, 76, 2374-2378. doi:10.1021/jo200164v

48. Wang, Q.-G.; Zhu, S.-F.; Ye, L.-W.; Zhou, C.-Y.; Sun, X.-L.; Tang, Y.; Zhou, Q.-L. Adv. Synth. Catal. 2010, 352, 1914-1919. doi:10.1002/adsc.201000129

49. Tan, B.; Candeias, N. R.; Barbas, C. F., III. J. Am. Chem. Soc. 2011, 133, 4672-4675. doi:10.1021/ja110147w

50. Zhong, F.; Han, X.; Wang, Y.; Lu, Y. Angew. Chem., Int. Ed. 2011, 50, 7837-7841. doi:10.1002/anie.201102094

51. Deng, H.-P.; Wei, Y.; Shi, M. Adv. Synth. Catal. 2012, 354, 783-789. doi:10.1002/adsc.201101012

52. Shi, Y.-L.; Shi, M. Adv. Synth. Catal. 2007, 349, 2129-2135. doi:10.1002/adsc.200700155

53. Deng, H.-P.; Wei, Y.; Shi, M. Eur. J. Org. Chem. 2011, 1956-1960. doi:10.1002/ejoc.201001660

54. Yang, Y.-L.; Pei, C.-K.; Shi, M. Org. Biomol. Chem. 2011, 9 , 3349-3358. doi:10.1039/c1ob00017a

55. Deng, H.-P.; Shi, M. Eur. J. Org. Chem. 2012, 183-187. doi:10.1002/ejoc.201101365

56. Deng, H.-P.; Wei, Y.; Shi, M. Org. Lett. 2011, 13, 3348-3351. doi:10.1021/ol201094f

57. Ito, M.; Osaku, A.; Kobayashi, C.; Shiibashi, A.; Ikariya, T. Organometallics 2009, 28, 390-393. doi:10.1021/om801042b

58. The crystal data of $3 r$ have been deposited in the CCDC with number 863228 (Supporting Information File 2).

59. Jiang, Y.-Q.; Shi, Y.-L.; Shi, M. J. Am. Chem. Soc. 2008, 130, 7202-7203. doi:10.1021/ja802422d

60. Plietker, B.; Niggemann, M. Org. Lett. 2003, 5, 3353-3356. doi:10.1021/ol035335a

\section{License and Terms}

This is an Open Access article under the terms of the Creative Commons Attribution License

(http://creativecommons.org/licenses/by/2.0), which permits unrestricted use, distribution, and reproduction in any medium, provided the original work is properly cited.

The license is subject to the Beilstein Journal of Organic Chemistry terms and conditions:

(http://www.beilstein-journals.org/bjoc)

The definitive version of this article is the electronic one which can be found at:

doi:10.3762/bjoc. 8.121 